\title{
SCHOOL NURSES: AN INDISPENSABLE RESOURCE FOR HEALTH PROMOTION IN ONTARIO'S CHILDREN AND ADOLESCENTS
}

\author{
DAGMARA MROCZKOWSKA ${ }^{*}$
}

\section{INTRODUCTION}

The promotion of health is a central goal of the Ontario government, not least because it is codified in the Health Protection and Promotion Act (HPPA). ${ }^{1}$ School nurses can be central to ensuring that physical, mental, and social health, including the prevention of disease and injury in children, are promoted. A reasonable interpretation of the HPPA supports the implementation of a robust school nurse program that will meet the health needs of children, yet school districts across Ontario do not have nearly enough resources to implement such a program.

A comprehensive school nurse program is supported by existing legislation and policy reasons. It is not ultra vires the statutory grant of authority under the HPPA to significantly increase the number of nurses in schools. Such an increase is endorsed by HPPA sections 5(4)(iv) and 6. These sections may be reasonably interpreted to include a full supply of nurses in the education system. Many policy reasons also support the implementation of nurses in the elementary and secondary school systems; however, a number of logistical and financial obstacles must be overcome in order to implement a comprehensive school nurse program. A significant increase in the availability of school nurses is the optimal method to fulfill the Ontario government's legislative objectives of protecting and promoting public health in its communities. I argue that the scope of practice of registered nurses places them in the best position to implement and ensure that the goals of the HPPA are met in Ontario's schools.

\section{THE LAW}

The first section of this paper begins with a brief legislative history to contextualize the HPPA's role in fulfilling the national objective of improving

Copyright $\odot 2019$ by DAGMARA MROCZKOWSKA.

* Dagmara Mroczkowska is a recent JD graduate from Western University. She holds a BA (Hons) in Philosophy from Queen's University and will be articling at an insurance defence litigation firm in Toronto as of August 2019. Dagmara extends her thanks to the Western Journal of Legal Studies team for their assistance in publishing this article.

${ }^{1}$ RSO 1990, c H.7 [HPPA]. 
community health before focusing on Ontario's current legislation, particularly sections 5(4)(iv) and 6 of the HPPA. The relevant sections of the legislation and its regulations and policy documents, in conjunction with the purpose and scheme of the HPPA as a whole, show that the provincial legislature creates provisions that require interaction between the health care and education systems. The HPPA and other legislation and regulations, as I will show, can and should be interpreted to support implementing significantly more nurses in school programs. Moreover, there are many important public policy reasons for doing so. The HPPA, as it currently stands, suggests that a complete and comprehensive health program supports an increased presence of nurses in Ontario's public elementary and secondary schools.

The HPPA was created to reflect Ontario's growing emphasis on preventive medicine. ${ }^{2}$ The HPPA was enacted in 1983 to replace the Public Health Act. In 1986, shortly after the HPPA was enacted, the World Health Organization (WHO) held the first International Conference on Health Promotion in Canada. The WHO shifted from a reactive to proactive approach on health, focusing on "a state of complete physical, mental and social well-being and not merely the absence of disease or infirmity." ${ }^{3}$ This new definition inspired the development of the Ottawa Charter for Health Promotion, recognized as "health promotion's founding document," 4 and revolutionized health care in Canada. It created a collaborative approach to health care delivery that emphasized the importance of prevention and the value of alliances between public sectors in achieving optimal health outcomes. ${ }^{5}$ Changes made to the HPPA after the creation of the Ottawa Charter supported this collaborative approach. In 1990, the HPPA prescribed public health services for schools to implement, including oral health assessments and immunization. ${ }^{6}$ Through these changes, Ontario committed itself to a program that recommends cooperation between schools and the health care community. This cooperation was further emphasized by Ontario's commitment to the Comprehensive School Health movement, a program through which provinces work

\footnotetext{
${ }^{2}$ Ontario, Legislative Assembly, Official Report of Debates (Hansard), 32-2, No 68 (8 June 1982) (Hon Mr Grossman), online: Legislative Assembly of Ontario <ola.org/en/legislative-business/housedocuments/parliament-32/session-2/1982-06-08/hansard\#P9_461> [perma.cc/3MCB-4WEP]. ${ }^{3}$ Louise Potvin \& Catherine M Jones, "Twenty-five Years After the Ottawa Charter: The Critical Role of Health Promotion for Public Health” (2011) 102:4 Can J Pub Health 244 at 244 (the definition of health was adopted from the preamble of the Constitution of the World Health Organization, and the Ottawa Charter is credited as a document that endorses and applies the definition in approaching health care programs).

${ }^{4}$ Ibid.

${ }^{5}$ Ibid at 244-45.

${ }^{6}$ School Health Programs and Services, RRO 1990, Reg 570, s 1(1).
} 
together to achieve the goal of effective health promotion. ${ }^{7}$ The historical shift in the approach to health since the enactment of the HPPA shows that student access to health care has become an important facet of the legislation.

The HPPA and its regulations prescribe cooperation between the boards of health and the education system. The relevant sections of the HPPA are sections $5(4)$ (iv) and 6(1): ${ }^{8}$

5 Every board of health shall superintend, provide or ensure the provision of health programs and services in the following areas:

...

4. Family health, including,

iv. preschool and school health services, including dental services, ... . ...

6(1) Every board of health shall provide such of the health programs and services as are prescribed by the regulations for the purposes of this section to the pupils attending schools within the health unit served by the board of health.

The words in sections 5(4)(iv) and 6 must be read harmoniously with the purpose and scheme of the HPPA. ${ }^{9}$ The purpose of the HPPA, as set out in section 2 , is "to provide for the organization and delivery of public health programs and services, the prevention of the spread of disease and the promotion and protection of the health of the people of Ontario." 10 In pursuit of this purpose, the Minister of Health, through the boards of health, is obliged to "superintend, provide or ensure" the provision of certain health programs and services in every district; these districts are otherwise known as "health units." 11 Health programs and services include those prescribed to "pupils attending schools within the health unit served by the board of health."12 This provides the

\footnotetext{
${ }^{7}$ Barbara G Ronson \& Carol MacDougall, "Background Paper on Health Promoting Schools Prepared for the Ministry of Health and Long-Term Care" (Paper updating OHPE Bulletin \#96.1 "The HealthPromoting School Movement," 13 January 2013) at 9, 12, online (pdf): Ontario Public Health Association <opha.on.ca/OPHA/media/Resources/Resource\%20Documents/cshbackgrounder.pdf?ext=.pdf $>$ [perma.cc/ULZ6-YTLF].

${ }^{8}$ HPPA, supra note 1, ss 5(4)(iv), 6(1).

${ }^{9}$ Elmer A Driedger, Constructions of Statutes, 2nd ed (Toronto: Butterworths, 1983) at 87. See also Re Rizzo \& Rizzo Shoes Ltd, [1998] 1 SCR 27 at para 21, Iacobucci J (citing Driedger with approval).

${ }^{10}$ HPPA, supra note 1 , s 2 .

11 Ibid, s 5.

${ }^{12}$ Ibid, s 6(1).
} 
Minister of Health with the authority to implement school health programs, and holds him or her accountable for their implementation. School health programs and services are prescribed by Regulation 570 under the $H P P A .{ }^{13}$ The prescribed programs involve oral health assessments, screening, and promotion; immunization for designated diseases, and recording and assessment of immunization status; and vision screening. ${ }^{14}$ In the case of immunization, the Minister of Health must ensure the immunization of students against certain infectious diseases through the Immunization of School Pupils Act. ${ }^{15}$ This Act grants the Minister of Health authority to suspend a student from school for a failure to be immunized, subject to certain conditions. ${ }^{16}$ Further, the Minister of Health has the authority to order vaccinations for individuals who are under sixteen years of age. ${ }^{17}$

Practice standards published under the authority of the HPPA are explicit in their requirement of collaboration between boards of health and school boards. Pursuant to section 7 of the HPPA, the Minister of Health "may publish public health standards for the provision of mandatory health programs and services and every board of health shall comply with them." 18 Under the legal authority of this section, the Minister of Health has published the Ontario Public Health Standards (the Standards). ${ }^{19}$ The HPPA operates in conjunction with the Standards to deliver health programs to the community. ${ }^{20}$ School health is specifically targeted by the Standards, with a goal " $[\mathrm{t}] \mathrm{o}$ achieve optimal health of school-aged children and youth through partnership and collaboration with school boards and schools." 21 The desired outcomes of the coordination between the boards of health and school boards include collection and use of data to address needs of the community; a decrease in health inequities; maintained awareness of relevant and current population needs impacting school children; and the

\footnotetext{
${ }^{13}$ Supra note 6.

${ }^{14}$ Ibid.

${ }^{15}$ RSO 1990, c I.1.

${ }^{16}$ Ibid, s 6; see Re Eastern Ontario Health Unit and ONA, 2005 CarswellOnt 11055 at para 10 (Ont Arbitration) [Re Cormier].

${ }^{17}$ HPPA, supra note 1, ss 22, 23; see Re Cormier, supra note 16 at para 20.

${ }^{18}$ HPPA, supra note 1, s 7; see also, Halton (Regional Municipality) v Bowman, 2015 ONCJ 270 at paras 8-9.

19 "Ontario Public Health Standards: Requirements for Programs, Services, and Accountability" (1 July 2018) at 8, online (pdf): Ontario Ministry of Health and Long-Term Care $<$ health.gov.on.ca/en/pro/programs/publichealth/oph_standards/docs/protocols_guidelines/Ontario_Public _Health_Standards_2018_en.pdf>[perma.cc/WP23-9JJP] [Standards].

${ }^{20}$ Ibid at 8 .

${ }^{21}$ Ibid at 51 .
} 
education of school boards, families, school children, and youth about healthy lifestyles. $^{22}$

The Standards outline a number of requirements in pursuit of these outcomes, including the collection, analysis, and reporting of data related to the health of school children and youth; providing population health information, such as social determinants of health and health inequities; development and implementation of programs of public health intervention to improve the health of school children and youth; and support to school boards and schools to "assist with the implementation of health-related curricula and health needs in schools." ${ }^{23}$ Curricula include programs that address physical and mental health, healthy eating behaviours, UV exposure, substance use, healthy sexuality, sleep, and oral health. ${ }^{24}$ The Standards emphasize the importance of "[a]n integrated surveillance and monitoring strategy" to ensure effective "planning, implementation, monitoring, and evaluation" of these programs and services. ${ }^{25}$ An effective implementation of these programs in a school setting is optimized by the physical availability of a health care professional who is able to conduct screenings and vaccinations, identify high-risk schools and individuals, and respond directly and adequately to each school's particular needs. The Standards support the intention of the HPPA to foster direct interaction between health professionals and schools.

The goals of the HPPA with respect to health promotion in schools align with the roles of school nurses. The goals of the HPPA are prevention of the spread of disease, and the promotion and protection of health. Although this link is not made explicitly clear in the legislation, the wording of the subsequently enacted Nursing Act suggests that registered nurses are best-equipped to advance these goals; particularly, the Nursing Act adopts the language of section 5(4)(iv) of the HPPA and captures its spirit: "[t]he practice of nursing is the promotion of health and the assessment of, the provision of care for and the treatment of health conditions by supportive, preventive, therapeutic, palliative and rehabilitative means in order to attain or maintain optimal function." 26 The foremost task of nurses is to promote health by assisting in health maintenance. This scope of practice is further elaborated in the Code of Ethics for Registered Nurses (the Code), to which registered nurses are bound as part of their regulatory process. ${ }^{27}$ In order to promote health and well-being under the Code, "nurses

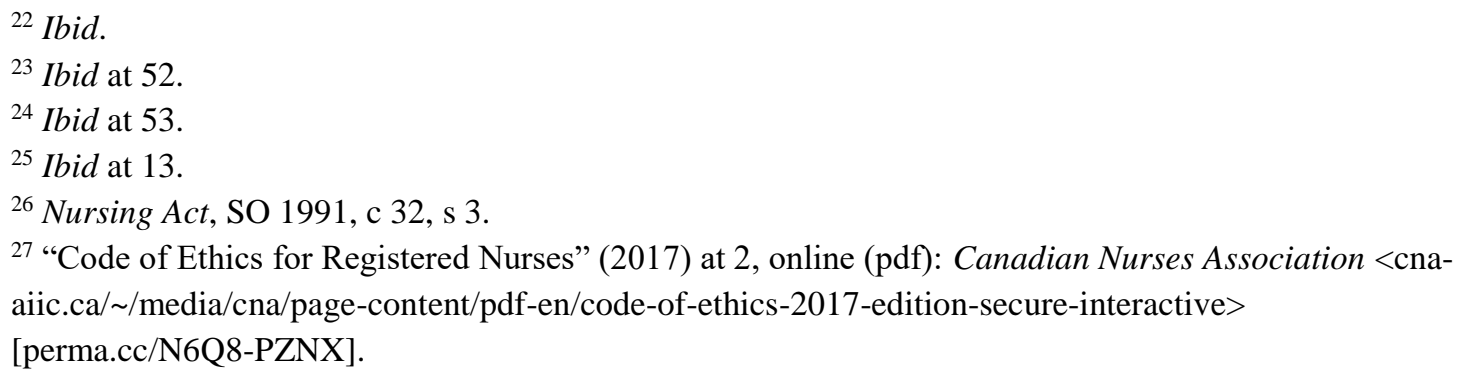


provide care directed first and foremost toward the health and well-being of persons receiving care, recognizing and using the values and principles of primary health care" (emphasis removed). ${ }^{28}$ The Code also specifies that nurses are advocates for health promotion and health equity who recognize the significance of social determinants of health, such as education, and advocate for policies and programs that address these determinants. ${ }^{29}$ This places nurses at the forefront of health promotion and prevention. They are relied on to implement health programs that attain health equity in many contexts, including education. Registered nurses, given their expertise, are uniquely equipped to implement and ensure that the goals of the HPPA are met in schools.

Registered nurses who have the opportunity to specialize in public and community health are uniquely equipped to be placed at the forefront of care in elementary and secondary schools. The first standard of public health nurses is health promotion, followed by other standards such as prevention, access, and equity. ${ }^{30}$ Public health nurses consider the impact of determinants of health, such as social and educational status, when developing health promotion strategies. ${ }^{31}$ In school, public health nurses provide education, group skill-building programs, and individual interventions to promote health. ${ }^{32}$ These practices embody the definition of health promotion as it relates to school health services under section 5(4)(iv) of the HPPA.

The most important indicator that school nurses may be considered as a health program under the HPPA is their current presence at school boards across Ontario. The School Health Guideline (the Guideline), which outlines the responsibilities of health units under the HPPA and the Standards, identifies the activities to be carried out by public health professionals in schools and school boards. ${ }^{33}$ The legal authority of the Guideline is derived from the HPPA, as it provides the mandated approaches to two of the requirements outlined in the Standards published under section 7 of the HPPA. ${ }^{34}$ Specifically, it outlines how a board of health must develop and implement a program

\footnotetext{
${ }^{28}$ Ibid at 10 .

${ }^{29}$ Ibid at $18-19$.

30 "Professional Practice Model \& Standards of Practice" (2011) at 9, online (pdf): Community Health

Nurses of Canada <chnig.org/wp-content/uploads/2016/02/chnc-standards.pdf> [perma.cc/HL7D-YYP8].

${ }^{31}$ Ibid at 10.

${ }^{32}$ Community Health Nurses Initiatives Group, "Healthy Schools, Healthy Children: Maximizing the Contribution of Public Health Nursing in School Settings (Version 2.0)" (April 2015) at 9, online (pdf): <chnig.org/wp-content/uploads/2016/02/School-Nursing-Paper-2.pdf> [perma.cc/DP3A-GUG5] [Community Health Nurses Initiatives Group, "Healthy Schools, Health Children”].

${ }^{33}$ Population and Public Health Division, Ministry of Health and Long-Term Care, "School Health Guideline, 2018" (2018), online (pdf): Ontario Ministry of Health and Long-Term Care $<$ health.gov.on.ca/en/pro/programs/publichealth/oph_standards/docs/protocols_guidelines/School_Health _Guideline_2018.pdf> [perma.cc/52RE-MR2Y].

${ }^{34}$ Ibid at 3.
} 
of public health interventions, and how a board of health must support school boards and schools to assist with the implementation of health-related curricula and health needs in schools. ${ }^{35}$ There are a number of activities that public health nurses can carry out within their scope of practice in schools and school boards. These activities include assessment, surveillance, and data analysis; creation and promotion of comprehensive action plans that include significant student participation and leadership; encouragement of youth to participate in health management and promotion; contribution to health policy across school boards; engaging youth in health initiatives; conducting evaluations; and recognizing the success of school health initiatives. ${ }^{36}$ These activities are aimed at health promotion as prescribed under section 5(4)(iv) and Regulation 570 of the HPPA. Moreover, these activities adhere to the Standards that operate under the HPPA. There currently exists a strong connection between the HPPA and school nurse programs in Ontario.

There is the potential for schools to reject the implementation of a health program under section 6(2) of the HPPA. Under this provision, the person or organization that operates the school must "[agree] to the provision of the particular health program or service to the pupils attending the school"; ${ }^{37}$ however, the ability of schools to reject health programs is subject to the decisions of the Lieutenant Governor in Council, who is in turn bound by the provisions of the Education Act. ${ }^{38}$

The Education Act includes a variety of provisions related to the health of Ontario's pupils. Nutritional standards require that food or beverages offered for sale in school cafeterias and vending machines do not contain more than the prescribed amount or percentage of trans fat, absent certain conditions. ${ }^{39}$ The prescribed amount is outlined in a regulation under the Education Act. ${ }^{40}$ There are also provisions that require the implementation of policies and guidelines with respect to bullying prevention and intervention. ${ }^{41}$ Lastly, there are provisions allowing for physical training programs ${ }^{42}$ and concussion protocols. ${ }^{43}$ The Education Act further allows for the implementation of additional health-related regulations: "[ $\mathrm{t}]$ he Lieutenant Governor in Council may make regulations prescribing, respecting and governing the duties of boards, so as to further

${ }^{35}$ Ibid at 3-4.

${ }^{36}$ Community Health Nurses Initiatives Group, "Healthy Schools, Health Children", supra note 32 at 19.

${ }^{37}$ HPPA, supra note 1 , s 6(2).

${ }^{38}$ Education Act, RSO 1990, c E.2.

${ }^{39} \mathrm{Ibid}$, ss 318-19.

${ }^{40}$ Trans Fat Standards, O Reg 200/08.

${ }^{41}$ Education Act, supra note 38, s 301(7.1).

${ }^{42}$ Ibid, s 12(1).

${ }^{43} \mathrm{Ibid}, \mathrm{s} 321(1)$. 
and promote the provincial interest in education." ${ }^{\prime 4}$ A regulation under this authority requires a board to "adopt and implement measures specified in the regulation to promote the health of the board's pupils." 45

Although there are no current regulations under the HPPA that mandate compliance with the health programs outlined in the Standards or the Guideline, the policies outlined therein reflect and expand the goals of enacted provisions under the Education Act. They address issues of nutritional, mental, and physical health, and preventive protocols for issues that affect students, such as concussions. The Standards identify the minimum expectations for public health programs and services with respect to these issues. A rejection of health programs under the HPPA, while possible, is precluded by some provisions of the Education Act; it also runs counter to provincial goals of improving health in school children and youth, which are based on concerns that were raised by school boards, parents, and local health agencies across Ontario long before the introduction of the HPPA. ${ }^{46}$ Currently, there is no indication that any school in Ontario has rejected health programs under section 6(2) of the HPPA.

A reasonable interpretation of the HPPA suggests that Ontario has a responsibility to provide every public elementary and secondary school with a nurse. The current school nurse program is inadequate to serve the legislative needs of the HPPA. It fails to adequately promote health in Ontario's schools and, as a result, fails to improve and maintain a healthy school community. In addition to legislative support, there are numerous policy reasons for the implementation of a more comprehensive school nurse program.

\section{THE POLICY}

Policy expectations support the presence of a full-time, on-site public health nurse at every public elementary and secondary school in Ontario. Students face numerous health issues that are not being adequately managed by school staff. School nurses make a positive impact in alleviating these issues through accessibility, trustbuilding, and community connection. A comprehensive school nurse program can also prevent tragedies that result in reactive legislation.

Students in elementary and secondary schools face a unique combination of health issues. These issues include obesity, sexual health issues, drug and alcohol abuse, nutritional deficiencies, mental health disorders, and bullying. ${ }^{47}$ Anger management,

\footnotetext{
${ }^{44}$ Ibid, s 11.1(1).

${ }^{45}$ Ibid, s 11.1(6)(e).

${ }^{46}$ Deputy Minister of Education, "Policy/Program Memorandum No 81" (19 July 1984), online: Ontario Ministry of Education <edu.gov.on.ca/extra/eng/ppm/81.html> [perma.cc/9WHU-FXSX].

${ }^{47}$ Standards, supra note 19 at 6, 8, 20, 29.
} 
impulse control, bullying, and harassment are also leading issues that need to be addressed among students. ${ }^{48}$ Many of these health issues cannot be dealt with outside of the school because students do not share them with family members, do not acknowledge them, or do not have the support or means to address them. Although teachers and principals undergo training for social management of students, effectively dealing with these serious health problems is beyond their scope of training and expertise. Yet, teachers, principals, and school staff are still the ones faced with the task of developing, implementing, and enforcing health policies because of the lack of school nurses. This places an undue burden on school administrators and regularly fails to meet the needs of students. By way of contrast, nurses are already equipped with the skills necessary to address these issues in students. In addition to performing physical acts such as inspections, injections, and screenings, nurses are authorized to address mental health issues under the Nursing $A c t .{ }^{49}$ Nurses are the face of health care for many students, and are confidants with whom students can discuss private health issues without fear of bias or disclosure.

Community health professionals have emphasized the importance of building a trusting relationship between health care providers and patients, and access to confidential health care builds such a relationship of trust between youth and the health care system. ${ }^{50}$ Trust in one's health care provider is especially important in a society that is overwhelmed with information on the Internet that can lead to the adoption of harmful and dangerous health practices. ${ }^{51}$ Providing school nurses is important to children and adolescents who may not have the time or the means to seek help regarding personal health issues for fear of reprehension from friends, guardians, or community members. The provision of school nurses grants students a sense of privacy and autonomy in dealing with health issues that translates into proactive health management as students grow older. A strong relationship with health care can only be built through time and exposure; only a consistently available nurse-or team of nurses — can successfully foster these bonds with students.

After the home, schools are the second-most influential environment in the lives of children and adolescents. In a policy statement, the Council on School Health said

${ }^{48} \mathrm{Ibid}$ at $6,52-53$.

${ }^{49}$ Nursing Act, supra note 26, s 4(4).

${ }^{50}$ Danielle Martin MD, Better Now: Six Big Ideas to Improve Health Care for All Canadians (Toronto: Penguin Random House, 2017) at 55 ("every individual should have a relationship with a primary care doctor or nurse practitioner").

${ }^{51}$ See Chmiliar v Chmiliar, 2001 ABQB 525 at paras 61, 65, Moen J (in this case, a child developed an irrational fear instilled by her mother such that she lost her capacity to make a rational decision in relation to vaccination; however, the court "did not order the vaccinations because on balance, her fear outweighs the benefits" at para 65). 
that "there is a recognized relationship ... between school nurse availability and student well-being and educational success." 52 The Guideline is based on the principle that "[h]ealthy students are better learners, and better educated individuals are healthier, making health and education interdependent."53 Ontario's public health sector recognizes the importance of schools as a setting for comprehensive health promotion and makes "[i]mproving and protecting the health and well-being of school-aged children and youth ... a priority." 54 It is important to provide sufficient access to health resources for children when they are in their formative years so that they may develop positive health habits into adulthood and influence the health habits of surrounding community members. Because of their intimate knowledge of the different health initiatives and programs within the community, school nurses provide a bridge between the school and external health services within the community. In this capacity, they are able to refer students, staff, and parents to the appropriate health avenues for a variety of issues that these individuals may be unable to address on their own. Nurses are in a unique position to facilitate the delivery of health care on a personal level. This is consistent with the Guideline's position that "the development and maintenance of effective partnerships and collaborations between boards of health and school communities ... is fundamental to effective public health practice." ${ }^{\prime 55}$ Community health is an important issue for Canadians, and nurses provide a significant benefit by alleviating barriers that prevent access to health information and care in the community.

Reports from school districts that have implemented comprehensive school nurse programs provide qualitative support for the positive impact of school nurses on the health of both students and the community at large. Students in communities with multiple full-time nurses at school showed an "increased ability to deal with problems, increased hopefulness, reduced worrying, improved relationships at school and at home, and better decision-making about healthy living, with respectable improvements in marks, schoolwork and attendance." 56 School staff identified nurses "as a resource to

\footnotetext{
${ }^{52}$ Council on School Health, "Role of the School Nurse in Providing School Health Services" (2008) at 1052, online (pdf): AAP News \& Journals Gateway <pediatrics.aappublications.org/content/pediatrics/121/5/1052.full.pdf> [perma.cc/4H4Z-CFBK].

${ }^{53}$ Population and Public Health Division, Ministry of Health and Long-Term Care, supra note 33 at 5. See also "What is Comprehensive School Health?" (2008), online (pdf): Joint Consortium for School Health <jcsh-cces.ca/upload/JCSH\%20CSH\%20Framework\%20FINAL\%20Nov\%2008.pdf> [perma.cc/N4LY-L2TJ].

${ }^{54}$ Population and Public Health Division, Ministry of Health and Long-Term Care, supra note 33 at 5.

55 Ibid.

${ }^{56}$ Community Health Nurses Initiatives Group, "Evidence for School Public Health Nurses” (April 2015) at 18, online (pdf): <ontariohealthyschools.com/uploads/2/1/7/6/21766954/evidence-school-phns.pdf> [perma.cc/YN9V-8T4S].
} 
assist teachers in helping students focus on school." 57 Mental health services at schools revealed that outcomes for students included "improved coping skills, improved problem-solving ability, improved mood and improved thinking patterns." "58 Sexual health services, where nurses were available to students approximately one day per week during the school year, yielded similar results. ${ }^{59}$ Both teachers and students sought the nurses as key resources because the nurses reduced barriers that students might have encountered if they were to go off-site for services; provided a comfortable and convenient environment for discussion; and, most importantly, provided access to appropriate sexual health information "through training provided by nurses to the teacher, classroom teaching, sexual health counselling and birth control provided to the students themselves."60 These programs illustrate the positive impact that school nurses can have on students, teachers, and members of the community. They embody Ontario's legislative goals for health promotion under the HPPA and show the potential for improved overall health that translates into social, academic, and personal successes for children and adolescents.

The lack of a comprehensive school nurse program leaves students vulnerable to otherwise preventable harms while at school. In Ontario, three tragic and preventable student deaths at school have resulted in legislation to prevent future occurrences. While nurses do not remove all human error, all three students would undoubtedly have benefited from a consistent school nurse presence and might still be alive today.

Sabrina's Law, 2005, ${ }^{61}$ was brought to the Legislative Assembly of Ontario after high school student Sabrina Shannon suffered fatal anaphylactic shock while eating lunch at her school cafeteria in 2003. No one knew how to respond when Sabrina fell into anaphylactic shock and she did not have her EpiPen with her at the time. ${ }^{62}$ Sabrina's Law mandates preventive anaphylactic policies at every school in Ontario. ${ }^{63}$ Its provisions invoke the same requirements as the HPPA and the Guideline. Nurses are equipped with the skills to react to anaphylactic shock, and they are in a position to understand life-threatening allergies, collect information from affected pupils, and create strategies to reduce risks at schools. They have the authority to educate students and school staff about how to react to anaphylactic shock, along with the ability to

${ }^{57}$ Ibid.

${ }^{58}$ Ibid at 19.

${ }^{59} \mathrm{Ibid}$ at $19-20$.

${ }^{60}$ Ibid at 20.

${ }^{61}$ SO 2005 , c 7 .

${ }^{62}$ Tamara Cherry, "Sabrina's Mom Agitates So Other Kids Won’t Die" (3 May 2007), online: The Star $<$ thestar.com/life/health_wellness/diseases_cures/2007/05/03/sabrinas_mom_agitates_so_other_kids_ wont_die.html> [perma.cc/NTU6-BBHH].

${ }^{63}$ Supra note 61, s 2(1). 
educate parents and the community about how to manage life-threatening allergies on a daily basis. Had a school nurse been attached to the school, it can be reasonably inferred that Sabrina and her condition would have been known to this nurse. As a necessary corollary, appropriate training and tools would have been readily available to assist Sabrina in her distress. These allergies are a well-known phenomenon in public health, and their management should have been enforced under the HPPA before Sabrina's untimely passing.

Ryan's Law (Ensuring Asthma Friendly Schools), $2015^{64}$ was passed after Ryan Gibbons, a 12-year-old boy with severe asthma, suffered a fatal asthma attack during recess at school. Ryan had his inhaler consistently taken away by teachers and locked in the principal's office as part of the school's policy. ${ }^{65}$ During his fatal asthma attack, he was unable to retrieve the inhaler from the principal's office. Prior to Ryan's Law, schools across Ontario had widely varying and conflicting policies regarding inhalers. ${ }^{66}$ This inconsistency seems to have been the result of a lack of education for school staff. ${ }^{67}$ Ryan's Law mandates that all Ontario school boards establish standardized asthma policies, which must include strategies to reduce the risks of an attack, emergency procedures, and educational tools for the community. ${ }^{68}$ The inhaler policy at Ryan's school, which kept inhalers locked away from severely asthmatic students, ran directly against the HPPA's mandate of providing health protection and preventing injury to school pupils. ${ }^{69}$ Given that public nurses are equipped and qualified to educate on health matters such as severe asthma, the presence of a nurse would likely have prevented the faulty inhaler policy from being implemented. This policy indicated the lack of communication between schools and the health care system; a school nurse would have provided the missing link in communication.

${ }^{64}$ SO 2015, c 3 [Ryan's Law].

${ }^{65}$ The Canadian Press, "Ontario Mom Urges Schools to Let Asthmatic Kids Carry Puffers" (8 December 2013), online: $C B C$ News <cbc.ca/news/canada/ottawa/ontario-mom-urges-schools-to-let-asthmatic-kidscarry-puffers-1.2455861> [perma.cc/4VXZ-4WSP].

66 "Ryan's Law Lets Kids With Asthma Carry Inhalers at School" (5 May 2015), online: Allergic Living (blog) <allergicliving.com/2015/05/05/ryans-law-lets-kids-with-asthma-carry-inhalers-at-school> [perma.cc/G289-TAXX].

${ }^{67}$ The Canadian Press, “After Son's Death Ontario Mom Urging Schools to Let Kids With Asthma Carry Puffers" (9 December 2013), online: CTV News <www.ctvnews.ca/canada/after-son-s-death-ontariomom-urging-schools-to-let-kids-with-asthma-carry-puffers-1.1580999>: ("[i]n some schools, students are not allowed to have [inhalers] outside of the principal's office, some [schools] have medical stations where teachers have pictures of students who need inhalers but still don't have [them] on hand, and in other schools [they have] to be in the teacher's desk, which doesn't help ... when [the children are] in the playground." In Ryan Gibbons' case, his mother "expressed frustration that the school Ryan attended his entire life, and [which] was well aware of his condition, assigned him the trombone in music class, which she felt made him more vulnerable to the fatal asthma attack").

${ }^{68}$ Supra note 64, ss 2-4.

${ }^{69}$ HPPA, supra note 1 at ss 5(4)(iv), 6. 
Rowan's Law (Concussion Safety), $2018^{70}$ implements a concussion safety protocol and amends the Education Act following the death of Rowan Stringer, a high school athlete who suffered two concussions within the same week during three school rugby matches. After her second concussion, she developed Second Impact Syndrome, which ultimately led to her untimely death. ${ }^{71}$ The event prompted a national call for inquiry into concussion protocols for student athletes. Prior to Rowan's Law, there were no concussion laws or consistent youth sport concussion management systems in Ontario or Canada. Rowan's Law incorporates themes of surveillance, prevention, detection, management, and awareness, all of which were recommended by an Advisory Committee set up after a coroner's inquest into Rowan's death. ${ }^{72}$ It requires that athletes, guardians, coaches, and educators review concussion awareness resources that are approved by the Minister of Tourism, Culture and Sport and discuss prevention, detection, and management of concussions. Schools must also implement protocols governing when a student athlete must be removed from play if they are suspected of having suffered a concussion, and what standards must be met before the athlete may return to play. ${ }^{73}$ These provisions all fall within a school nurse's scope of practice. The prevalence of sports at many schools, and their importance to students, strongly suggests that preventive education about concussions should be provided under the health promotion mandate. Nurses, who are competent and authorized to educate, diagnose, monitor, and refer concussed students to immediate and intensive care, are particularly suited for the successful implementation of Rowan's Law.

It is not difficult to imagine that a comprehensive school nurse program akin to the type allowed by the HPPA would have prevented the large gaps in school health policy that led to the deaths of Sabrina Shannon, Ryan Gibbons, and Rowan Stringer. It should not solely be the responsibility of teachers and principals to provide health care strategies to students when there is a provincial commitment to increase access to health services in schools. Such an expectation places an unfair burden on the education system and shifts the health care system's responsibility to individual schools. Given nurses' scope of practice, their training in health promotion, and their skills in diagnosis, health care interventions, education, and administrative tasks, nurses provide the best hope for students who face health risks at school.

\footnotetext{
70 SO 2018, c 1 [Rowan's Law].

71 "Rowan Stringer Ignored Concussion Symptoms Days Before Death" (19 May 2015), online: $C B C$ News <cbc.ca/news/canada/ottawa/rowan-stringer-ignored-concussion-symptoms-days-before-death1.3077245> [perma.cc/HBK3-5TNX].

72 “Creating Rowan's Law: Report of the Rowan's Law Advisory Committee” at 4 (9 September 2017), online (pdf): Ministry of Tourism, Culture and Sport <mtc.gov.on.ca/en/publications/rowan_report.pdf> [perma.cc/9A6K-AQ6Y].

${ }^{73}$ Rowan's Law, supra note 70.
} 
Policy provides a number of reasons to place a nurse at every public elementary and secondary school in Ontario. School nurses provide greater access to health for students, build ongoing relationships of trust between youth and health care providers, and create a bridge between individuals and community health services. Moreover, their presence alleviates many of the dangers faced by students with health risks. Although policy supports a comprehensive school nurse program, it is important to consider the logistical hurdles of implementing such a program. The benefits of public health nurses in schools must be weighed against their costs to ensure that the proposed school nurse program is not only mandatory, but feasible.

\section{THE LOGISTICS}

A comprehensive school nurse program has logistical implications that present barriers to implementation. Presently, Ontario's school nurse program is implemented inconsistently across the province and prevents nurses from utilizing their full scope of practice. Provincial budgets make it difficult to fund a comprehensive school nurse program. Informational gaps must be filled before the program's budgetary needs can be determined and a plan of action can be formed. With more resources and planning, a comprehensive school nurse program is feasible.

The current school nurse program in Ontario remains inadequate to provide access to health care and management for children and adolescents. Delivery of services to students in Ontario is varied and inconsistent. ${ }^{74}$ Currently, fewer than three-quarters of health units in Ontario have public health nurses "providing at least monthly or biweekly support to both elementary and secondary schools."75 Over a quarter of Ontario's schools lack meaningful support from health professionals. Moreover, while some health units allocate their resources by having a school nurse attend once or twice a month, others focus their resources at either the elementary or secondary school level, but not both. ${ }^{76}$ This is an organizational gap that prevents students from accessing an important health resource and fails to support healthy community development.

Current school nurses do not utilize the full extent of their training in Ontario's public school system. Public health nurses are registered nurses with a baccalaureate in nursing. They are authorized to perform a variety of acts, such as using instruments, administering injections and medications, and addressing mental illness in their patients. $^{77}$ They are also uniquely equipped with the ability to strategize, plan, and

\footnotetext{
${ }^{74}$ Community Health Nurses Initiatives Group, "Healthy Schools, Health Children”, , supra note 32 at $17,22$.

${ }^{75} \mathrm{Ibid}$ at 3.

${ }^{76}$ Ibid.

${ }^{77}$ Nursing Act, supra note 26, s 4.
} 
educate schools about health. ${ }^{78}$ These abilities pertain to students and school staff equally. School nurses can ensure that adequate health policies are enforced at schools and preventable accidents are avoided. A school nurse can guarantee that the health curriculum is appropriate, accurate, and thorough. Finally, a school nurse relieves the pressure on teachers and principals to act as paramedical staff. While it is important for school staff to be able to respond to medical emergencies, it is unfair to expect teachers to be the only medical resource for children who may suffer from high-risk emergencies while under their care. School nurses provide safety and support to staff who deal with medical emergencies.

Under the current system, school nurses do not utilize their full scope of practice in the delivery of their services. For example, 42 percent of public health units offer one-on-one counselling and 39 percent facilitate support or small groups promoting mental health in school. ${ }^{79}$ By way of contrast, a small number of districts do have a robust school nurse program, through which nurses provide "counseling services to either or both elementary and secondary school students. They work with students on stress or coping-related issues, self-esteem, sexual health, relationship difficulties with peers and parents, and lifestyle issues." 80 Public health nurses share these responsibilities with other professionals, such as "social workers, guidance counselors, and psychologists." 81 These scenarios create a positive environment for the promotion of health in students, but they occur only in a minority of health units.

Nurses are also subject to unequal nurse-to-student ratios that make delivery of meaningful health services very difficult. Depending on the size of a health unit, school nurses are responsible for between 400 to 14,000 students. This is a significant burden that adversely impacts the connection nurses can make with their schools and the kinds of programs that nurses can provide. ${ }^{82}$ As a result, there are differences in the roles that school nurses perform depending on their assigned health unit: some only provide minimally required duties, while others are able to expand their services into sexual health programs, one-on-one counselling, and mental health services. ${ }^{83}$ Regional satisfaction reports, completed by students, reflect the desire for more school nurses in order to fulfill the needs of students. ${ }^{84}$ Only those nurses with a smaller student-to-nurse ratio are able to respond to these needs and implement the recommendations of the

${ }^{78}$ Community Health Nurses Initiatives Group, “Healthy Schools, Health Children”, supra note 32 at 19.

${ }^{79}$ Ibid at 11 .

${ }^{80}$ Ibid at 12 .

81 Ibid.

82 Ibid at 4.

${ }^{83}$ Ibid at 3-4.

${ }^{84}$ Community Health Nurses Initiatives Group, "Evidence for School Public Health Nurses", supra note 56 at 20. 
Guideline. The varied availability of school nurses and high student-to-nurse ratios limit access to health resources for students and diminish the role of nurses in the school community. As a result, the Government of Ontario fails to uphold its legislative objectives of promoting health in the school community.

The inconsistencies in Ontario's school nurse program stem from ongoing funding and organizational issues. Fluctuating provincial budgets and shifts in population health strategies contribute to the reduction or outright elimination of school nurses. ${ }^{85}$ Healthcare spending in Ontario was projected to reach just under $\$ 62$ billion in $2018 .{ }^{86}$ Of this total, just under $\$ 6$ billion was expected to be spent on public health. ${ }^{87}$

Those who provide health care funding are reluctant to allocate large sums of money toward health promotion and prevention due to the constant rise in costs of secondary and tertiary interventions. In its 2012 analysis of Canada's performance in health, the Conference Board of Canada noted that, "[f]unding for health promotion and disease prevention invariably competes with the financial demands of the [acute] healthcare system ... It is often politically difficult to deny urgent needs in the present to invest in the future." 88 Interest in public and population health ebbs and flows, often in response to crises such as SARS, the West Nile virus, and the Walkerton water crisis in Ontario. ${ }^{89}$ Other crises, such as heart disease, obesity, and smoking-related cancer, do not invoke the same sense of urgency for public funding, despite increasing awareness of the seriousness of these issues and the need for provincial management strategies. Nevertheless, it remains difficult to justify funding for preventive health care in the face of reactive health delivery needs.

The requirement of a school nurse at every public elementary and secondary school places an additional burden on the provincial budget, but exact figures cannot be accurately determined because current information regarding school nurse employment in Ontario is largely unavailable. The most reliable document available to determine current statistics on nurses is the College of Nurses of Ontario's Membership Statistics

\footnotetext{
${ }^{85}$ Community Health Nurses Initiatives Group, "Healthy Schools, Health Children", supra note 32 at 3.

86 "National Health Expenditure Trends, 1975 to 2018" (November 2018), online: Canadian Institute for Health Information <cihi.ca/en/health-spending/2018/national-health-expenditure-trends> [perma.cc/JTV8-YMRG] (the data can be found in table D3: "Public-sector expenditures" as a downloadable spreadsheet).

87 Ibid.

88 "The Costs and Performance of Canada's Health System" (10 October 2013) at 3, online (pdf): Canadian Nurses Association <cna-aiic.ca/-/media/cna/files/en/the_costs_performance_canadas_ health_system_e.pdf> [perma.cc/V3CA-2W9X].

${ }^{89}$ Ibid.
} 
Report $2017 .^{90}$ The report reveals that, as regards schools, there were 442 employers available for registered nurses, 321 employers available for registered practical nurses, and six employers available for registered nurses in the extended class. ${ }^{91}$ Unfortunately, this document broadly defines the term "school" to include "elementary and secondary, public or private." 92 It does not specify how many employers actually hired nurses, how many nurses each employer needed, or the names of the employers. Moreover, it does not provide information on how many nurses are currently employed by school boards or individual schools. As of 2017-2018, there were a total of 4,850 public elementary and secondary schools across 72 public school boards, with over 2 million students. ${ }^{93}$ There is no readily available data that shows how many nurses are employed in each health unit, but the number of employers stated as available in the Membership Statistics Report 2017 reveals that available positions for school nurses fall far short of the number of schools in Ontario that require them. Without solid employment numbers, it is difficult to assess Ontario's current need to fill school nurse positions, which in turn presents challenges for the drafting of a budget proposal to the government and adds an additional hurdle to the implementation of a cohesive school nursing program.

Logistically, the implementation of the proposed school nurse program would require the recruitment of and training and payment of salary for an increased number of nurses in Ontario. Some schools may also require more than one nurse on site, making it even more difficult to provide an accurate figure with regard to the potential cost of rolling out the program. It should be sufficient to conclude that increasing the contingent of school nurses in Ontario will require significant additional public health funding. ${ }^{94}$

Increased health education leads to increased population health. When students learn about and live healthy lifestyles early in life, it can be argued that less secondary and tertiary intervention will be required for the management of preventable diseases

\footnotetext{
90 “Membership Statistics Report 2017” (2017), online (pdf): College of Nurses of Ontario <cno.org/globalassets/docs/general/43069_stats/2017-membership-statistics-report.pdf> [perma.cc/4XU9-CBJX].

${ }^{91}$ Ibid at 74, 85, 88 .

92 Ibid at 94.

93 "Education Facts: 2017-2018" (preliminary results as of 1 October 2018), online (pdf): Ontario Ministry of Education <edu.gov.on.ca/eng/educationfacts.html> [perma.cc/V6U4-KETR] (the total number of elementary and secondary students as of October 1, 2018 was 2,020,301).

${ }^{94}$ For an example of public nurse wages in Ontario, see "Highlights of Collective Agreement Changes as a Result of the Kaplan Award and Items in Agreement Between ONA and Participating Hospitals," online (pdf): Ontario Nurses' Association <ona.org/wpcontent/uploads/ona_hospitalcahighlightdoc_20180731f.pdf> [perma.cc/8R2V-GRTJ].
} 
that are directly linked to unhealthy lifestyles in the future. However, despite the availability of positive qualitative results by school districts that have implemented comprehensive school nurse programs, there is no quantitative data available to supplement the argument that school nurses increase student and public health. For example, it is unknown how many times students visit school nurses, how many referrals have been made to outside community health resources, how many prescriptions have been given, and how many minor interventions have been performed by school nurses. The lack of quantitative information about school nurse programs and their efficacy poses difficulties in creating a budget plan and convincing the government that this mandatory program is feasible.

In order to plan and implement a comprehensive school nurse program, more information about the availability, salary, and current existence of school nurses is necessary. This information will allow for the development of a budgetary plan that can be accommodated by Ontario's health budget. It will also lead to a better understanding of the roles of school nurses that can be implemented uniformly across Ontario. A uniform school nurse program is the best means by which to ensure the safety of our students and relieve the current burden on school staff to promote and protect student health. The benefits of a school nurse program extend beyond schools and into communities in a manner that lifts burdens on both education and health care systems. The impacts of the health and education system must be quantified in order to track the efficacy of the school nurse program and identify any needs for improvement of the program. A logistical plan that includes budget and organization planning will support legal and policy arguments for the implementation of a school nurse program. If the gaps in information can be filled, then the school nurse program will no longer remain a policy-based argument subject to political debates but will rather be a call to action by the public health community for Ontario to productively fulfill its goals under the HPPA.

\section{CONCLUSION}

School nurses play an important role in achieving the goal of health promotion in Ontario, particularly for children and adolescents. The HPPA provides a reasonable expectation of a comprehensive school nurse program in Ontario. Subsequent legislation, regulations, and guidelines support the role of school nurses in health promotion.

Social and policy expectations and considerations provide ample support for the presence of school nurses at every elementary and secondary school, and they provide valuable educational tools to students, school staff, and parents. They also encourage positive relationships between individuals and the health care system through increased 
access to health services. Lastly, they bridge the gap between individuals and external health services in the broader community.

The presence of school nurses is necessary for the development of consistent school policies that ensure student safety and prevent tragedies on school grounds. Ontario's current lack of oversight with regard to school health policies allows otherwise preventable dangers to our children and adolescents to persist; a robust program for school nurses would place onto school premises those who are best equipped to provide greater safety measures. The implementation of a comprehensive school nurse program will allow nurses to work within their full scope of practice and provide all the necessary tools for students and staff to maintain a healthy school community. This will lead to greater academic success and long-term health for students and, in turn, create a positive impact on community health.

Numerous case studies of school nurse programs provide examples of the positive impact that school nurses have on overall population health. When students are healthy, they attend school, achieve academic success, and take the initiative to maintain their own health. At home, students share their knowledge and encourage their family members and friends to make healthy choices. In this way, increased health education leads to increased population health. When children and adolescents learn to live healthy lifestyles early in life, they grow into healthy adults. By supporting student health, nurses can play a key role in promoting the health of families and the larger community. The majority of children and adolescents in Ontario are enrolled in public education. Without a strategy for ensuring the presence of school nurses at every public elementary and secondary school, Ontario misses out on one of the most accessible opportunities to strengthen community health. With the right information, a thorough strategy, and dedication to the cause, a comprehensive public school nurse program is well within reach. The resources put forth toward public school nurses will not only promote the health of Ontarians today, but will benefit community health for generations to come. 